\title{
Article
}

\section{Sex addiction: therapist perspectives}

Brewer, Gayle and Tidy, Paul

Available at http://clok.uclan.ac.uk/18880/

Brewer, Gayle ORCID: 0000-0003-0690-4548 and Tidy, Paul (2019) Sex

addiction: therapist perspectives. Sexual and Relationship Therapy, 34 (1). pp. 40-53. ISSN 1468-1994

It is advisable to refer to the publisher's version if you intend to cite from the work. http://dx.doi.org/10.1080/14681994.2017.1347618

For more information about UCLan's research in this area go to http://www.uclan.ac.uk/researchgroups/ and search for < name of research Group>.

For information about Research generally at UCLan please go to http://www.uclan.ac.uk/research/

All outputs in CLoK are protected by Intellectual Property Rights law, including Copyright law. Copyright, IPR and Moral Rights for the works on this site are retained by the individual authors and/or other copyright owners. Terms and conditions for use of this material are defined in the policies page.

\section{CLoK}

Central Lancashire online Knowledge www.clok.uclan.ac.uk

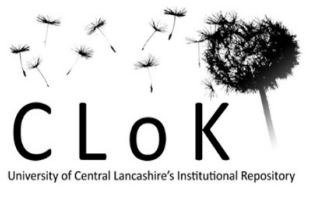




\section{Sex Addiction: Therapist Perspectives}

Gayle Brewer, Ph.D, ${ }^{1,3}$ and Paul Tidy, $\mathrm{MSc}^{2}$

${ }^{1}$ School of Psychology, University of Liverpool, Liverpool, UK.

${ }^{2}$ School of Psychology, University of Central Lancashire, Preston, Lancashire, UK.

${ }^{2}$ To whom correspondence should be addressed at School of Psychology, University of Liverpool, Liverpool, L69 7ZX, UK.

Gayle Brewer, Ph.D.

School of Psychology

University of Liverpool

Liverpool

L69 7ZX, UK

(44) $151-795-8563$

Email: Gayle.Brewer@liverpool.ac.uk 
Sexual addiction may be defined as sexual behaviour that is "compulsive and yet continues despite adverse consequences" (Carnes \& Adams, 2013, p5). Knowledge and understanding of sexual addiction has been impaired by the use of multiple labels, definitions, and assessment procedures, hence the present study investigated therapist perspectives and experiences of assessing and treating the condition. Interviews were conducted with nine Psychosexual Therapists and subjected to Interpretive Phenomenological Analysis. Three superordinate themes emerged from the analysis. These were Distress, Risk, and Treatment. The Distress theme included three subthemes: Stress and Coping; Suicidal Ideation; and Partner Experience. Three subthemes formed the Risk theme: Physical Safety; Disease, Dysfunctions, and Pregnancy; and Co-Addiction. The Treatment theme contained three sub-themes: Awareness; Assessment and Diagnosis; and Successful Therapy. Findings have important implications for the diagnosis and treatment of sexual addiction. Future research should investigate these themes further and introduce interventions to support the safety and well-being of sexual addiction clients.

Keywords: Interpretative Phenomenological Analysis; Sexual Addiction; Sexual Compulsion; Therapy; Treatment 


\section{Introduction}

Sexual addiction may be defined as sexual behaviour that is "compulsive and yet continues despite adverse consequences" (Carnes \& Adams, 2013, p5). It is characterised by the failure to resist impulses, pleasure or release following sexual behaviour, increased tension prior to sexual activity, and a lack of control (Goodman, 1990). Understanding of this condition is however hindered by the use of multiple labels, definitions, and assessment procedures. For example, though the label sexual addiction was originally proposed and perhaps as a consequence is most widely accepted, literature refers to addiction, compulsion, dependence, impulsivity, and excessive sexual behaviour (see Gold \& Heffner, 1998 for a review). Furthermore, some professional bodies deny the existence of such a condition and consider sexual addiction to be a myth or social construct. They argue that within a dominant monogamous heterosexual culture, non-relational sex and excessive sex have been pathologised and reject attempts to diagnose sexual addiction. Furthermore, for those accepting that a condition exists which should be termed sexual addiction, substantial variation occurs with regards to the conceptualisation of addiction and the degree to which treatment providers view addiction as a disease or a coping mechanism (Russell, Davies, \& Hunter, 2011).

Estimates of sexual addiction prevalence range between three and ten percent (Carnes, 1991; Cooper, Morahan-Martin, Mathy, \& Maheu, 2002), though the prevalence of sexual addiction within the U.K. remains unclear (Griffiths \& Dhuffar, 2014). Men, and particularly men who have sex with men, homosexual men, and bisexual men, are more likely to self-diagnose or be diagnosed with sexual addiction (Kuzma \& Black, 2008; Missildine, Feldstein, Punzalan, \& Parsons, 2005). Furthermore, men and women may differ in their experience of sexual addiction. For example, Skegg, Nada-Raja, Dickson, and Paul (2010) report that women 
engage in concurrent sexual relationships, large numbers of opposite sex partners, or sex with partners from the internet whereas men described same-sex attraction and paying for heterosexual sex. These sex differences may be exacerbated by societal perceptions of male and female sexual behaviour, shame, and stigma which may disproportionately impact on female clients. Of course, attempts to accurately determine the prevalence of sex addiction are hindered by the lack of agreement which surrounds definition and diagnosis. Furthermore, though standardised approaches have been developed such as the Sexual Addictions Screening Test (Carnes, 1989) these are not typically intended for minority groups (e.g., women and non-heterosexual clients).

Those experiencing sexual addiction may engage in frequent sexual encounters, sexual risk taking, compulsive masturbation, frequent use of pornography, and obsessive thoughts (e.g., Briken, Habermann, Berner, \& Hill, 2007; Grov, Parsons, \& Bimbi, 2010). Shame and secrecy, a lack of control, and a separation of intimacy and sexual behaviour may also occur. The intensity, occurrence, and scope of sexual addiction increases across time and may extend to exploitation or illegal behaviour (Irons \& Schneider, 1994). Hence addiction can result in distress, reduced quality of life, and poor physical and psychological health which impact on personal, relational, and occupational pursuits (e.g., Kuzma \& Black, 2008; Odlaug, et al. 2013). Indeed though the compulsive behaviours and obsessive thoughts appear to temporarily reduce stress and anxiety, they produce an unhealthy self-perpetuating cycle.

Therapist led treatment approaches are available to support those with sexual addiction including a twelve step programme, group therapy, and pharmacological interventions (see Gold \& Heffner, 1998 for a review). Relatively few treatment evaluations are available however and "current evidence on efficacy, efficiency and security of psychotherapeutic treatment of sexual addiction is insufficient to guide clinicians in terms of the best techniques 
and the most appropriate duration of treatment" (Garcia, et al. 2016, p59). It is therefore important to consider therapist accounts which may reveal important information about client experiences, the therapeutic relationship, and the condition itself which can inform the treatment process and improve current practice (e.g., Mackereth, Parekh, \& Donald, 2012; Rybovic, Halkett, Banati, \& Cox, 2008). Furthermore, it is important to obtain therapist perspectives as previous research has documented the manner in which therapist characteristics, beliefs, and behaviours influence client outcomes (Degan, Seymour-Hyde, Harris, \& Berry, 2016; Moyers \& Miller, 2013).

The current study employed interpretative phenomenological analysis to investigate therapist perspectives of assessing and treating sexual addiction. The approach has been successfully employed to understand patient and therapist perspectives of a range of conditions. For example, interpretative phenomenological analysis has highlighted those factors influencing the incidence of premature ejaculation, the impact of the condition on partners, and barriers to effective assessment and diagnosis (Brewer \& Tidy, 2016).

\section{Method}

\section{Participants}

Participants $(N=9)$ were qualified Psychosexual Therapists identified via the Association for the Treatment of Sexual Addiction and Compulsivity (ATSAC) website. Each participant had provided therapy for sexual addiction for at least one year and was a registered member of a relevant organization or professional body such as the College of Sexual and Relationship Therapists (COSRT), British Association of Counselling and Psychotherapy (BACP), or the Association for the Treatment of Sexual Addiction and Compulsivity (ATSAC). Participant age ranged from 32 to 61 years $(M=49.78, S D=8.12)$ and post qualified experience ranged from 4 to 28 years $(M=13.67, S D=7.57)$. Eight therapists worked in private practice only 
and one therapist worked in both private practice and NHS settings. Primary counselling modalities were integrated $(n=4)$, psychodynamic $(n=3)$, and person-centred $(n=2)$. See Table 1 for full participant details.

[Table 1 near here]

\section{Materials and Procedure}

Prior to interview, participants completed a questionnaire identifying demographic status, professional training history, and client profile. Individual semi-structured interviews were then conducted at the participant's place of work, with only the interviewer and interviewee present. Each interview lasted between 39 and 69 minutes $(M=47.11, S D=9.43)$ resulting in 424 minutes of interview material. Open-ended questions prompted participants to report and reflect on their experiences. The interview schedule was prepared following established guidelines (Smith, 1995) and questions were framed to obtain information about the aetiology and experience of sexual addiction and the recovery process. Interviews were recorded on a portable hand-held device and transcribed verbatim. Interviews were anonymised at the point of transcription and subjected to Interpretive Phenomenological Analysis (Smith, 1996).

Interpretative Phenomenological Analysis adopts a phenomenological, hermeneutic, and idiographic perspective (Smith, Flowers, \& Larkin, 2009) which allows researchers to describe, interpret, and understand the lived experience of a population and the manner in which individuals make sense of this lived experience. The researcher listened to the recordings, repeatedly read the interview transcripts to aid familiarisation, and made notes of significant areas of the text. Following further readings of the transcripts, notes were formed into emergent themes. Relationships between emerging themes were then identified and these were grouped into superordinate themes and sub-themes. The analytic process was validated by discussions between the first and second author, during which the appropriateness of each 
theme and sub-theme was established. Principles proposed by Smith, et al. (2009) were adhered to throughout the data collection and analytic process to provide rigour and cohesion.

\section{Results}

Interpretative Phenomenological Analysis of interview transcripts generated three superordinate themes: (1) Distress; (2) Risk; and (3) Treatment. Each superordinate theme contained a number of sub-themes, as detailed in Table 2.

[Table 2 near here]

\section{Distress}

\section{Stress and Coping}

Therapists reported that stressful situations may act as triggers for sexual behaviour and described sexual addiction as a coping strategy for stress and past trauma. Specifically, sexual addiction serves to regulate emotions e.g., to replace negative emotions. These maladapted coping strategies first appear to work for the clients but as the behaviours escalate and the clients engage in therapy they begin to realise that they are not coping. In addition, the consequences or potential consequences of discovery (e.g., dissolution of a relationship) exacerbated the stress experienced by clients. The clients are encouraged to express their emotional needs to their family and friends and increase contact with them by replacing the time spent engaging in sexual behaviour with healthy social activity.

\footnotetext{
"Sex addiction is a form of emotion regulation, absolutely, $100 \%, 100 \%$, it is a selfsoothe mechanism, there is no doubt. They think they cope with it in their working day but actually when they look back they realised that they didn't cope with it at all, it is treadmill, they just keep going." (Therapist 1)

"Behavioural addictions are related to emotional regulation and coping. Again it seems that many people haven't been able to develop a way to regulate their emotions, to cope
} 
with stressful or upsetting events and therefore these behaviours are being used. One particular client uses massage parlours at stressful times or having a difficult time, he was using the massage parlours to relax, to calm and to cope with stress. They aren't really connecting with people, so a lot of the consequences of that is that they actually don't have anywhere to turn, they don't have friendships, the relationships aren't emotionally intimate." (Therapist 2)

"So for some people it is a way of forgetting, numbing out, and zoning out. For some people it is a way of lifting them out a numb place. For some people it is a way of giving them some energy, for some people it is bringing them down from hyperarousal."

(Therapist 5)

\section{Suicidal Ideation}

Five therapists spoke of sexual addiction clients presenting with suicidal thoughts. The suicidal thoughts were closely associated with discovery and relapse. Furthermore, whilst the remaining therapists reported no experience of clients presenting suicidal thoughts two mentioned that partners may have presented with suicidal thoughts, though this was believed to be of low risk.

\footnotetext{
"I have not had anybody with suicidal tendencies. I have had people that have told me their partners have been suicidal." (Therapist 1)

"I have had one client in particular recently who made a very serious suicide attempt when he thought that he was going to be exposed, which would have meant him losing his family. I would say about half of them will have had suicidal thoughts." (Therapist 3) "About $20 \%$ of my clients have been suicidal....just this week a client who I would have thought on the surface was not at risk at all because he is very wealthy, he seems to be fairly happy, he said that he felt suicidal. I asked him how often you feel like killing yourself, he replied about once a month, I asked if he had thought how he would do it. He said oh yes absolutely." (Therapist 7)
}

\section{Partner Experience}

Each therapist commented on the manner in which sexual addiction impacts on the partner.

Two therapists reported that partners can become obsessed with checking up on their partner 
and therefore exhibit compulsive behaviour themselves. Therapists also spoke about partners experiencing anxiety and depression which can lead to poor health and require medication.

One therapist highlighted the importance of ongoing partner support and the extent to which dismissive, hostile, or angry behaviour can negatively impact on the recovery process.

Therapists described partner trauma following a disclosure of sexual addiction and indicated that this commonly results in longer recovery times than the person with the addiction. Hence both the addict and partner require therapy.

"The partner is often very, very anxious or they may get depressed. Very often they will go on to medication, antidepressants at some stage, then they have time off work as they feel that their whole life has spiralled out of control." (Therapist 3)

"When dealing with sex addiction, partner support is very important, because it doesn't matter how well the addict is doing during the session, if when they go home and their partner is dismissive, hostile and keeps reminding them that they have done something bad, "how can you do that to me". This can knock them back. So the partner will need support in terms of understanding why, and that question can be ongoing for months." (Therapist 4)

"Partners of people with sex addiction have a dreadful time. For the partner who has discovered or just had a disclosure, that's when their trauma starts, and the recovery for partners in some respect can be a much lengthier, harder process than it is for people presenting the sex addiction." (Therapist 5)

\section{Risk}

\section{Physical Safety}

Therapists described a range of sexual behaviours which placed clients at risk of physical harm (e.g., assault). These behaviours often included anonymous meetings and cruising and the practice of Bondage and Dominance, Sadism and Masochism (BDSM). The risk to physical safety caused distress to both clients and therapists.

"The majority, if they meet people, are just oral sex, being tied up or humiliated, hit or whatever, but actual penetration, unless it is paid ladies or paid men, then there is 
penetration, but if they are just meeting or cruising, it's not penetration at all...The most severe risky sex my clients talk about is bondage and being hit but not auto-

asphyxiation." (Therapist 1)

"I think the risky behaviours is a biggie because in terms of opportunistic people going onto the internet, trying to find someone to have sex with and then meeting them in public. One of the women was actually trying to recreate a rape scene. She was trying to have sex somewhere public with someone she didn't know, with a man she didn't know, and she was quite excited by the idea of rape. So the amount of risks involved with the behaviours she was undertaking was phenomenal. She could actually be killed because she was going in dark places, down the back of bars, down side streets, really dangerous situations." (Therapist 2)

"They are often quite risky; they want to have sex in a fairly public place. It is not that they want a relationship, because they will often have sex with somebody minutes after meeting them but they will often be quite risky...A client who came for therapy, so frightened, he had chatted to somebody online, didn't really know her and met up with her in a flat and she tied him up and asphyxiated him till he passed out, and he thought oh my God, next time I could be dead, so he was really afraid of that." (Therapist 3)

\section{Disease, Dysfunctions, and Pregnancy}

Five therapists described their clients' experience of sexually transmitted infections and sexual dysfunctions. It emerged that clients often practice unsafe sex and that the impact of these diseases and disorders can extend to partners. One therapist commented that clients may repeatedly present at sexual health clinics with concerns about sexually transmitted infections and sexual disorders (such as erectile dysfunction or premature ejaculation) though their sexual addiction is not identified or addressed by the service. Three therapists spoke about pregnancy, births, or termination. These included termination following anonymous sex and childbirths resulting from extramarital relationships.

"There is a risk of pregnancy. I have had a couple of clients who have had a termination of pregnancy because they have had sex with a stranger and got pregnant." (Therapist 3) "They will be meeting people they don't know, maybe sex with strangers and that can increase the risk of STI's or HIV. With females it could be pregnancy. When you talk about safe sex with them rationally they will say yes that is what I should be doing but 
when they were going through that addiction circle, everything just goes out of the window, so it is very unlikely that they will practice safe sex. If they become infected with any STI's potentially they can pass this onto their partners." (Therapist 4)

"In my experience the clients with sex addiction have had difficulties with usually either premature ejaculation or erectile dysfunction for the men." (Therapist 6)

\section{Co-Addiction}

Each therapists identified other compulsive behaviours such as co-addictions or crossaddictions which may increase the risks posed to clients. These included issues associated with alcohol, gambling, shopping, exercise, and recreational drugs. One therapist highlighted genetic factors associated with sexual addiction (which may therefore influence other addictive behaviours) reflecting research in the field of epigenetics which has identified links between addiction and biological genetic gene expression.

"They tend to do other things, such as binge drink, binge eating, and other addictive behaviour. Sometimes it may be gambling as well, but it is not uncommon to have cross addiction." (Therapist 4)

"Clients report a history or present with other compulsive behaviours such as gambling, shopping, smoking, alcohol consumption.” (Therapist 6)

"About $30 \%$ of my clients probably have some kind of cross-addiction as well."

(Therapist 7)

\section{Treatment}

\section{Awareness}

Each therapist reported that the provision for sexual addiction is limited and provided primarily by private practice or by religious organisations. Three therapists commented on the limited awareness of sexual addiction amongst healthcare professionals and the general counselling community and provided examples of sexual addiction not being identified or assessed. This may reflect a reluctance to discuss sexual behaviour among healthcare professionals. 


\begin{abstract}
"Within the counselling community, I don't think there is a particularly high level of awareness. They don't recognise that there is a therapy for it, there is still quite a low awareness of sex addiction and sex addiction therapy. A client referral I had said they worked together for eighteen months previously and this hadn't been assessed or detected." (Therapist 2)

"I think the general awareness and genuine understanding of the problem is pretty shocking amongst other health professionals and that can have a significant impact on clients in terms of reinforcing shame, not being signposted to the right places for appropriate services. People who are trying to work with it who do not understand anything about sexuality or addiction." (Therapist 7)

"Some people are being seen by doctors but nobody is actually asking the right questions" (Therapist 8)
\end{abstract}

\title{
Assessment and Diagnosis
}

All therapists commented on client assessment and diagnosis. Interviewees received mostly self-referral clients with the few remaining referrals provided by other counsellors or therapists. Self-referrals commonly presented with a self-diagnosis of sexual addiction though therapists reported being tentative with their use of sexual addiction as a label or diagnosis. In particular, those interviewed stated that the client's perception and experience was more important than the label. One therapist commented on the lack of diagnostic criteria in DSM V which may contribute to the tentative nature of providing a diagnosis due to uncertainty about diagnostic criteria. Overall, clients expected to receive a diagnosis and felt relief when this was provided; there could however be resistance to a diagnosis of addiction.

\footnotetext{
"They invariably turn up on the first day and say "I am a sex addict" I say let's look at this broader thing and do the assessment first. So what I say to them is you have turned out positive for addiction issues around sexual behaviour or we can call that out of control sexual behaviour, whichever fits better." (Therapist 1) "Some people may self-diagnose, some people have been diagnosed by their partners. We sit lightly to the label, we might actually say well that is the sort of thing that we would describe as someone who has a sex addiction problem but it is not the label that counts but their actual experience." (Therapist 5)
} 
"Sometimes people believe drug and alcohol addictions may be their primary addiction, in fact, it may not be, it may be that sex addiction is the primary addiction, so there is the question of assessing which comes first. I have not had a client that didn't see it as a positive thing. Again I don't do it as a label, I talk about more behaviours or showing signs than actually "oh yes you are a sex addict".” (Therapist 6)

\section{Successful Therapy}

Each therapist spoke about the importance of an integrated approach involving psychoeducation, cognitive behavioural therapy, and behaviour change based interventions incorporating motivational interviewing techniques. Empathy towards the client and partner were believed to be particularly important. Four therapists also commented on the lies told within and outside of the treatment sessions and the subsequent difficulties those with sexual addiction experience developing trust with the therapist. Successful treatment often focused on a couple developing an appreciation of each other's difficulties, understanding of their processes and feelings, and the re-establishment of trust and intimacy, allowing clients to recognise that their behaviour is inconsistent with their need for an emotionally close relationship.

\footnotetext{
"I think you have got to have a therapist who is willing to challenge, because the addicts are accomplished liars. I am not saying they lie all the time, because I think as they begin to trust you they will open up and be very honest, but I think as a therapist you have got to be very, very empathic towards that, but on the other hand you have got to be willing to challenge when they are lying. As you get to know the person you also get to know when they are telling the truth, not always, but often you will know." (Therapist 3) "We require the cooperation and alliance with the client about how much motivation they have, whether they are coming of their own accord or whether they are coming because they have been discovered using porn or sex outside their marriage, their partners are expecting them to come and fix it." (Therapist 4)
}

\section{Discussion}


Interpretative Phenomenological Analysis revealed three superordinate themes (1) Distress;

(2) Risk; and (3) Treatment. Nine sub-themes emerged; these were Stress and Coping, Suicidal Ideation, Partner Experience, Physical Safety, Disease, Dysfunctions, and Pregnancy, Co-Addiction, Awareness, Assessment and Diagnosis, and Successful Treatment.

\section{Distress}

Sexual activity was viewed as a coping mechanism which at first appeared to regulate emotion though the maladaptive nature of this approach later became clear to clients. Findings are consistent with previous research indicating that sexual behaviour may be used to lower pain, anger, and fear (Hughes, 2010). It is therefore essential for successful treatment to include interventions which support the development of adaptive coping mechanisms. In particular, as clients often lack social support (Torres \& Gore-Felton, 2007) they may be encouraged to strengthen their social networks.

Therapists commented on the incidence of suicidal ideation both amongst clients and their partners. Findings are consistent with previous online research demonstrating increased suicide risk among those with sexual addiction (de Tubino Scanavino, et al. 2013). Risk of discovery in particular influenced suicidal ideation. Findings are also consistent with greater suicide risk amongst those attracting police attention for sexual offences (King et al. 2015) and demonstrate the importance of effective sexual addiction treatment.

Partners were believed to experience considerable distress, extending in some circumstances to anxiety, depression, and compulsive behaviour. Findings are consistent with research suggesting that sexual addiction influences the psychological well-being of the partner and the quality of the romantic relationship (Schneider, 2000). However, previous research indicates that sexual addiction is associated with an insecure attachment style (Weinstein, Katz, Eberhardt, Cohen, \& Lejoyeux, 2015; Zapf, Greiner, \& Carroll, 2008) and additional 
research is required to determine the extent to which specific factors (e.g., the addiction itself or other relationship dynamics) influence partner distress.

Risk

The increased prevalence of dating sites and mobile apps has provided greater opportunities for anonymous encounters and clients frequently placed themselves at risk. These situations included meeting in high crime areas and with strangers. Clients were therefore at substantial risk of physical harm. There is a paucity of research investigating sex addiction victimisation and future studies should investigate these experiences and consider interventions to safeguard vulnerable clients.

Clients often practiced unsafe sex leading to sexually transmitted infections and unplanned pregnancy. Findings are consistent with previous research indicating that sexual addiction increases the risk of sexually transmitted infections and is a barrier to disease prevention efforts (Kalichman \& Cain, 2004; Reece, Plate, \& Daughtry, 2001). Sexually transmitted infections may result in shame, stigma, or guilt (Malta, et al. 2007) whilst unplanned pregnancy and termination are associated with a range of adverse consequences including emotional distress, anxiety, depression, and substance use (e.g., Lauzon, Roger-Achim, Achim, \& Boyer, 2000; Thorp, Hartmann, \& Shadigan, 2003). Future studies should further consider the consequences of sexual addiction and the promotion of protective behaviours such as condom use.

All therapists reported that clients presented with co-addictions; these included addiction to alcohol, gambling, and illegal substances. This is consistent with previous reports of coaddiction amongst those with sexual addiction (Carnes, Murray, \& Charpentier, 2005; Odlaug, et al. 2003; Swisher, 1995). Research suggests that comorbid sexual and substance addictions may be successfully treated concurrently (Hartman, Ho, Arbour, Hambley, \& 
Lawson, 2012). It may however be difficult to identify the primary addiction and recommendations for the effective treatment of sexual addiction remain inconsistent. Further, for some clients, a successful detoxification programme may be required prior to commencement of the sexual addiction therapy and referral to a rehabilitation facility may be appropriate. Additional research is required to establish the relationship between sexual addiction and other addictions and the manner in which available treatments improve client well-being.

\section{Treatment}

Therapists commented on the low level of awareness amongst health professionals and counsellors and the inadequate provision available to support sexual addiction. This is consistent with previous reports of misdiagnosis and under diagnosis (Sussman, Lisha, \& Griffiths, 2011; Swisher, 1995) and reports from mental health professionals themselves that they do not feel competent to treat problematic sexual behaviour (Short, Wetterneck, Bistricky, Shutter, \& Chase, 2016). This situation may reflect a general reluctance to discuss sexual behaviour (Gott, Galena, Hinchliff, \& Elford, 2004). It is therefore difficult for health care professionals and therapists, without specific training, to work with or identify sexual addiction. Indeed therapists reported that those with sexual addiction repeatedly received medical attention (e.g., attended sexual health clinics) but sexual addiction was not discussed and therefore further support was not provided. Hence, there is a need for further training amongst health care professionals, particularly those providing sexual health treatment.

Clients often presented via self-referral and provided a self-diagnosis of sexual addiction, suggesting some understanding or awareness of the condition amongst the general population. Future research should investigate perceptions of the various terms employed by researchers and practitioners (e.g., compulsion, impulsivity, dependence) and the manner in 
which these are perceived by the general population. In particular, whether the term addiction is more or less stigmatising than other terms and more or less likely to encourage help seeking and disclosure. Additional studies may investigate the manner in which the lack of agreement with regards to terminology and definitions has impacted on the assessment and diagnosis process.

Treatment typically included a range of techniques such as cognitive behavioural therapy, trauma work, psychodynamic therapy, and psychoeducation. Counselling skills and empathy in particular were important. In part, this may serve to address the stigma and shame associated with sexual conditions. It is consistent with the importance of empathy reported by Swisher (1995). Of course recommended treatments vary between therapists and future research should consider the manner in which provider characteristics (e.g., level or type of training) influence perceptions of sexual addiction and related practice. Further research is also required to establish levels of client honesty and the extent to which this impacts on treatment success. Whilst therapists in the present study appeared to be aware of client deception, less experienced therapists may not be and additional training or support may be required.

\section{Limitations and Future Research}

The current study employed a small sample which whilst limiting the number of therapists contributing allows an inherently rich analysis that may be constrained by larger sample sizes (Smith, et al. 2009). The present study recruited therapists predominantly working in private practice and therefore treat clients who (a) can afford to pay for treatment and (b) are seeking support. Furthermore, clients were typically young to middle aged men with female partners. Subsequent research should explore the themes identified in the current study with a larger, more diverse sample. In particular, as therapist perspectives and experiences may vary, 
contributions should be obtained from therapists who do not associate with the Association for the Treatment of Sexual Addiction and Compulsivity (ATSAC). These studies may consider the importance of both client and therapist characteristics. For example, few studies have considered sexual addiction amongst women which may reflect misunderstanding or the belief that few women experience sexual addiction and should be addressed (Ferree, 2001). Furthermore, the values held by therapists appear to influence the assessment of sexual addiction (Hecker, Trepper, Wetchler, \& Fontaine, 1995), suggesting considerable variation in client experience.

To conclude, interviews were conducted with nine psychosexual therapists and subjected to interpretative phenomenological analysis. Three superordinate themes were identified; these were Distress, Risk, and Treatment. The Distress theme contained three sub-themes: Stress and Coping; Suicidal Ideation; and Partner Experience. The Risk theme consisted of the Physical Safety, Disease, Dysfunctions, and Pregnancy, and Co-Addiction sub-themes. Finally, the Treatment theme contained three sub-themes: Awareness; Assessment and Diagnosis; and Successful Therapy. Findings have important implications for the treatment of sexual addiction. Future research should further investigate these themes in a wider, more diverse sample, and introduce interventions to support the safety and well-being of sexual addiction clients.

\section{References}

Brewer, G., \& Tidy, P. (2016). Premature ejaculation: Therapist perspectives. Sexual and Relationship Therapy, 32, 22-35. doi:10.1080/14681994.2016.1188200

Briken, P., Habermann, N., Berner, W., \& Hill, A. (2007). Diagnosis and treatment of sexual addiction: A survey among German sex therapists. Sexual Addiction \& Compulsivity, 14, 131-143. doi:10.1080/10720160701310450

Carnes, P.J. (1989). Contrary to love. Minneapolis, MN: CompCare Publishers. 
Carnes, P. (1991). Out of the shadows: Understanding sexual addiction. Minneapolis, MN: CompCare Publishers.

Carnes, P., \& Adams, K.M. (2013). Clinical management of sex addiction, New York, NY: Routledge.

Carnes, P.J., Murray, R.E., \& Charpentier, L. (2005). Bargains with chaos: Sex addicts and addiction interaction disorder. Sexual Addiction \& Compulsivity, 12, 79-120.

Cooper, A., Morahan-Martin, J., Mathy, R.M., \& Maheu, M. (2002). Toward an increased understanding of user demographics in online sexual activities. Journal of Sex \& Marital Therapy, 28, 105-129.

Degnan, A., Seymour-Hyde, A., Harris, A., \& Berry, K. (2016). The role of therapist attachment in alliance and outcome: A systematic literature review. Clinical Psychology \& Psychotherapy, 23, 47-65. doi: 10.1002/cpp.1937

de Tubino Scanavino, M., Ventuneac, A., Abdo, C.H.N., Tavares, H., do Amaral, M.L.S.A., Messina, B., dos Reis, S.C., Martins, J.P.L.B., \& Parsons, J.T. (2013). Compulsive sexual behaviour and psychopathology among treatment-seeking men in Sao Paulo, Brazil. Psychiatry Research, 209, 518-524. doi:10.1016/j.psychres.2013.01.021

Ferree, M.C. (2001). Females and sex addiction: Myths and diagnostic implications. Sexual Addiction \& Compulsivity, 8, 287-300. doi:10.1080/107201601753459973

Garcia, F.D., Assumpcao, A.A., Malloy-diniz, L., De Freitas, A.A.C., Delavenne, H., \& Thibaut, F. (2016). A comprehensive review of psychotherapeutic treatment of sexual addiction. Journal of Groups in Addiction \& Recovery, 11, 59-71. doi:10.1080/1556035X.2015.1066726

Gold, S.N., \& Heffner, C.L. (1998). Sexual addiction: Many conceptions, minimal data. Clinical Psychology Review, 18, 267-381. doi: 10.1016/S0272-7358(97)00051-2

Goodman, A. (1990). Addiction: Definition and implications. British Journal of Addiction, 85, 1403-1408. doi: 10.1111/j.1360-0443.1990.tb01620.x

Gott, M., Galena, E., Hinchcliff, S., \& Elford, H. (2004). "Opening a can of worms": GP and practice nurse barriers to talking about sexual health in primary care. Family Practice, 21, 528-536. doi:10.1093/fampra/cmh509 
Griffiths M.D., \& Dhuffar M.K. (2014). Treatment of sexual addiction within the British National Health Service. International Journal of Mental Health and Addiction, 12, 561-571. doi: 10.1007/s11469-014-9485-2

Grov, C., Parsons, J.T., \& Bimbi, D.S. (2010). Sexual compulsivity and sexual risk in gay and bisexual men. Archives of Sexual Behavior, 39, 940-949. doi:10.1007/s10508009-9483-9

Hartman, L.I., Ho, V., Arbour, S., Hambley, J.M., \& Lawson, P. (2012). Sexual addiction and substance addiction: Comparing sexual addiction treatment outcomes among clients with and without comorbid substance use disorders. Sexual Addiction \& Compulsivity, 19, 284-309. doi:10.1080/10720162.2012.735515

Hecker, L.L., Trepper, T.S., Wetchler, J.L., \& Fontaine, K.L. (1995). The influence of therapist values, religiosity and gender in the initial assessment of sexual addiction by family therapists. The American Journal of Family Therapy, 23, 261-272. doi:10.1080/01926189508251356

Hughes, B. (2010). Understanding 'sexual addiction' in clinical practice. Procedia Social and Behavioral Sciences, 5, 915-916. doi:1016/j.sbspro.2010.07.210

Irons, R.R., \& Schneider, J.R. (1994). Sexual addiction: Significant factor in sexual exploitation by health care professionals. Sexual Addiction \& Compulsivity: The Journal of Treatment and Prevention, 1, 198-214. doi:10.1080/10720169408400043

Kalichman, S.C., \& Cain, D. (2004). The relationship between indicators of sexual compulsivity and high risk sexual practices among men and women receiving services from a sexually transmitted infection clinic. The Journal of Sex Research, 41, 235241. doi:10.1080/00224490409552231

Kuzma, J.M., \& Black, D.W. (2008). Epidemiology, prevalence, and natural history of compulsive sexual behavior. Psychiatric Clinics of North America, 31, 603-611. doi:10.1016/j.psc.2008.06.005

King, C., Senior, J., Webb, R.T., Millar, T., Piper, M., Pearsall, A., Humber, N., Appleby, L., \& Shaw, J. (2015). Suicide by people in a community justice pathway: Populationbased nested case-control study. The British Journal of Psychiatry, 206, 1-2. doi: 10.1192/bjp.bp.114.154831 
Lauzon, P., Roger-Achim, D., Achim, A., \& Boyer, R. (2000). Emotional distress among couples involved in first-trimester induced abortions. Canadian Family Physician, 46, 2022-2040.

Mackereth, P., Parekh, J., \& Donald, G. (2012). Providing therapies to the opposite sex: Views of complementary therapists working in clinical and private practice settings. Complementary Therapies in Clinical Practice, 18, 154-158. doi:10.1016/j.ctcp.2012.05.001

Malta, M., Bastos, F.I., Strathdee, S.A., Cunningham, S.D., Pilott, J.H., \& Kerrigan, D. (2007). Knowledge, perceived stigma, and care-seeking experiences for sexually transmitted infections: A qualitative study from the perspective of public clinic attendees in Rio de Janeiro, Brazil. BMC Public Health, 7, 1. doi: 10.1186/1471$2458-7-18$

Missildine, W., Feldstein, G., Punzalan, J.C., \& Parsons, J.T. (2005). S/he loves me, s/he loves me not: Questioning heterosexist assumptions of gender differences for romantic and sexually motivated behaviors. Sexual Addiction \& Compulsivity, 12, 6574. doi:10.1080/10720160590933662

Moyers, T.B., \& Miller, W.R. (2013). Is low therapist empathy toxic? Psychology of Addictive Behaviors, 27, 878-884. doi: 10.1037/a0030274

Odlaug, B.L., Lust, K., Schreiber, L.R.N., Christenson, G., Derbyshire, K., Harvanko, A., Golden, D., \& Grant, J.E. (2013). Compulsive sexual behavior in young adults. Annals of Clinical Psychiatry, 25, 193-200.

Reece, M., Plate, P. L., \& Daughtry, M. (2001). HIV prevention and sexual compulsivity: The need for an integrated strategy of public health and mental health. Sexual Addiction \& Compulsivity, 8, 157-167. doi:10.1080/10720160127565

Russell, C., Davies, J.B., \& Hunter, S.C. (2011). Predictors of addiction treatment providers' beliefs in the disease and choice models of addiction. Journal of Substance Abuse Treatment, 40, 150-164. doi:10.1016/j.jsat.2010.09.006

Rybovic, M., Halkett, G. K., Banati, R. B., \& Cox, J. (2008). Radiation therapists' perceptions of the minimum level of experience required to perform portal image analysis. Radiography, 14, 294-300. doi:10.1016/j.radi.2007.07.004 
Schneider, J.P. (2000). Effects of cybersex addiction on the family: Results of a survey. Sexual Addiction \& Compulsivity: The Journal of Treatment and Prevention, 7, 3158. doi:10.1080/10720160008400206

Short, M.B., Wetterneck, C.T., Bistricky, S.L., Shutter, T., \& Chase, T.E. (2016). Clinicians' beliefs, observations, and treatment effectiveness regarding clients' sexual addiction and internet pornography use. Community Mental Health Journal, 1-12. doi:10.1007/s10597-016-0034-2

Skegg, K., Nada-Raja, S., Dickson, N., \& Paul, C. (2010). Perceived “out of control”' sexual behavior in a cohort of young adults from the Dunedin Multidisciplinary Health and Development Study. Archives of Sex Behavior, 39, 968-978. doi:10.1007/s10508-0099504-8

Smith, J.A. (1995). Semi-structured interviewing and qualitative analysis. In J. A. Smith, R. Harre, \& L. van Langenhove (Eds.). Rethinking methods in psychology. London: Sage.

Smith, J.A. (1996). Beyond the divide between cognition and discourse: Using Interpretative Phenomenological Analysis in health psychology. Psychology and Health, 11, 261271. doi:10.1080/08870449608400256

Smith, J.A., Flowers, P., \& Larkin, M. (2009). Interpretive phenomenological analysis: Theory, method and research. London: Sage.

Sussman, S., Lisha, N., \& Griffiths, M. (2011). Prevalence of the addictions: A problem of the majority or the minority? Evaluation and the Health Professions, 34, 3-56. doi: $10.1177 / 0163278710380124$

Swisher, S.H. (1995). Therapeutic interventions recommended for treatment of sexual addiction / compulsivity. Sexual Addiction \& Compulsivity, 2, 31-39. doi:10.1080/10720169508400064

Thorp, J.M., Hartmann, K.E., \& Shadigian, E. (2003). Long-term physical and psychological health consequences of induced abortion: Review of the evidence. Obstetrical \& Gynecological Survey, 58, 67-79.

Torres, H.L., \& Gore-Felton, C. (2007). Compulsivity, substance use, and loneliness: The loneliness and sexual risk model (LSRM). Sexual Addiction and Compulsivity, 14, 6375. doi:10.1080/10720160601150147 
Weinstein, A., Katz, L., Eberhardt, H., Cohen, K., \& Lejoyeux, M. (2015). Sexual compulsion: Relationship with sex, attachment and sexual orientation. Journal of Behavioral Addictions, 4, 22-26. doi:10.1556/JBA.4.2015.1.6

Zapf, J.I., Greiner, J., \& Carroll, J. (2008). Attachment styles and male sex addiction. Sexual Addiction \& Compulsivity, 15, 158-175. doi:10.1080/10720160802035832 
Table 1: Participant Characteristics

\begin{tabular}{|c|c|c|c|c|c|c|}
\hline No & Age & Sex & Location & Work History & $\begin{array}{l}\text { Primary } \\
\text { Modality }\end{array}$ & $\begin{array}{l}\text { Sex } \\
\text { Addiction } \\
\text { Cases in } \\
\text { Current } \\
\text { Practice }\end{array}$ \\
\hline 1 & 50 & $\mathrm{~F}$ & Private & $\begin{array}{l}11 \text { yrs as a Psychotherapist and } 5 \text { yrs as a } \\
\text { Psychosexual Therapist }\end{array}$ & Person Centred & $80 \%$ \\
\hline 2 & 32 & $\mathrm{~F}$ & Private & $\begin{array}{l}4 \text { yrs as a Couple Therapist and } 1 \mathrm{yr} \text { as a } \\
\text { Sexual Addiction Therapist }\end{array}$ & $\begin{array}{l}\text { Eclectic - } \\
\text { Integrated }\end{array}$ & $20 \%$ \\
\hline 3 & 61 & $\mathrm{~F}$ & Private & $\begin{array}{l}28 \text { yrs as a Couple Therapist and } 21 \text { yrs as a } \\
\text { Psychosexual Therapist }\end{array}$ & Psychodynamic & $40 \%$ \\
\hline 4 & 48 & M & $\begin{array}{l}\text { Private \& } \\
\text { NHS }\end{array}$ & $\begin{array}{l}18 \text { yrs as a Psychotherapist and } 5 \text { yrs as a } \\
\text { Psychosexual Therapist }\end{array}$ & Person Centred & $80 \%$ \\
\hline 5 & 55 & M & Private & 20 yrs as a Couple Therapist & Integrated & $70 \%$ \\
\hline 6 & 45 & M & Private & $\begin{array}{l}5 \text { yrs as a Couple Therapist and } 1 \text { yr as a } \\
\text { Sexual Addiction Therapist }\end{array}$ & $\begin{array}{l}\text { Psychodynamic, } \\
\text { Systemic, \& CBT }\end{array}$ & $25 \%$ \\
\hline 7 & 52 & $\mathrm{~F}$ & Private & $\begin{array}{l}15 \mathrm{yrs} \text { as an Addiction Therapist, and } 10 \mathrm{yrs} \\
\text { as a Psychosexual Therapist and Sexual } \\
\text { Addiction Therapist }\end{array}$ & Integrated & $100 \%$ \\
\hline 8 & 55 & M & Private & $\begin{array}{l}10 \text { yrs as a Couple Therapist and } 3 \text { yrs as a } \\
\text { Sexual Addiction Therapist }\end{array}$ & Psychodynamic & $25 \%$ \\
\hline 9 & 50 & M & Private & $\begin{array}{l}12 \text { yrs as an Addiction Therapist and } 2 \text { yrs as } \\
\text { a Sexual Addiction Therapist }\end{array}$ & Integrated & $40 \%$ \\
\hline
\end{tabular}


Table 2: Superordinate and Sub-Themes

\begin{tabular}{ll}
\hline Superordinate Theme & Sub-Theme \\
\hline Distress & Stress and Coping \\
& Suicidal Ideation \\
& Partner Experience \\
Risk & Physical Safety \\
& Disease, Dysfunctions, and Pregnancy \\
& Co-Addiction \\
Treatment & Awareness \\
& Assessment and Diagnosis \\
& Successful Therapy \\
\hline
\end{tabular}

